\title{
FORMATION OF THE STATE-SELECTED CH RADICAL BEAM AND ITS APPLICATION TO THE CH + NO REACTION
}

\author{
M. TAKEZAKI, H. OHOYAMA, T. KASAI* and K. KUWATA \\ Department of Chemistry, Faculty of Science, Osaka University, Toyonaka, Osaka \\ 560 Japan
}

(Received 16 March, 1994)

The $\mathrm{CH}\left(\mathrm{X}^{2} \Pi\right)$ radical beam was produced via the decomposition of methanol by a dc-discharge in a pulsed supersonic beam. The $\mathrm{CH}$ radical beam was rotationally state-selected and separated from other discharge products by using an electrostatic hexapole field. The chemiluminescence from the reaction of $\mathrm{CH}$ in the $13 / 2,3 / 2,3 / 2>$ state with $\mathrm{NO}$ was measured under the crossed beam condition. The wavelength region of the present chemiluminescence confirms no $\mathrm{NH}\left(\mathrm{A}^{3} \Pi\right)$ formation. The formation of $\mathrm{HCN}(\mathrm{X})$ and/or $\mathrm{OH}\left(\mathrm{X}^{2} \Pi\right)$ is tentatively proposed.

KEY WORDS: $\mathrm{CH}$, radical beam, dc-discharge, state-selection, hexapole

\section{INTRODUCTION}

$\mathrm{CH}$ radical is one of the most reactive and simplest organic free radicals. It is well known as an important intermediate on the various reaction systems in the fields from the planetary atmosphere to the hydrocarbon combustion.

There have been many studies on the reaction of $\mathrm{CH}$ with $\mathrm{NO}$ using the flow and the shock tube methods. However, the reaction mechanisms have not been clearly identified and the conflicting experimental results have often been reported about the identification of products of the elementary reactions. For example, Lichtin et al. ${ }^{1}$ and Nishiyama et al. ${ }^{2}$ have reported that the $\mathrm{NH}\left(\mathrm{A}^{3} \Pi\right)$ was main product from the reaction of $\mathrm{CH}$ and NO. On the other hand, Dean et al. ${ }^{3}$ have concluded that the primary channel was $\mathrm{HCN}(\mathrm{X})$ formation and $\mathrm{NH}\left(\mathrm{A}^{3} \Pi\right), \mathrm{NH}\left(\mathrm{X}^{3} \Sigma\right)$ and $\mathrm{OH}\left(\mathrm{X}^{2} \Pi\right)$ were not detected in this reaction system. These conflicts could be caused by interferences from unavoidable side reactions in those experiments. Because the formation of a radical as reactant requires decomposition of a precursor or reactions of appropriate reactants, we are obliged to get a mixture of reactants. Therefore, the identification of the product is extremely difficult without separation of a desired radical from the decomposed mixture. Furthermore, in the experimental conditions such as the flow and the shock tube methods, the secondary collision of the net 
products is unavoidable. For these reasons, lack of direct measurements has prevented us from clear understanding of the mechanism as an elementary reaction.

In order to detect the net product, it is indispensable to prepare the experimental conditions, in which the pure $\mathrm{CH}$ radical reacts with $\mathrm{NO}$ under the single collision conditions. The combination of an electrostatic hexapole field and a supersonic beam is very useful for the accomplishment of these conditions. Since the rotational statedensity of diatomic radical in the $\Pi$ state like $\mathrm{CH}$, is very low owing to the large rotational constant and the definite rotational quantum number of $\Omega$, fine state, the rotational cooling in the supersonic beam effectively concentrates the population in a few lower rotational states and enhances the beam intensity in the single rotational states which are selectively focused at characteristic hexapole voltages. This state selection also reduces the contribution of obstructive species which have the widespread rotational distribution.

In the present work, ${ }^{4}$ the pulsed $\mathrm{CH}\left(\mathrm{X}^{2} \Pi\right)$ radical beam was produced by the decomposition of methanol by the dc-discharge in the supersonic beam. The separation of $\mathrm{CH}$ from other decomposed mixture was performed using the electrostatic hexapole field through its rotational $\mid \mathrm{J} \Omega \mathrm{M}>$ state selection, where $\mathrm{J}$ is the total angular momentum, and $\Omega$ and $M$ are its projections on the molecular axis and on the electric field, respectively. This method was applied to detect the chemiluminescence from the reaction of the $\mathrm{CH}$ radical in $\mid 3 / 2,3 / 2,3 / 2>$ state with NO. Judging from the wavelength region of the chemiluminescence, no formation of $\mathrm{NH}\left(\mathrm{A}^{3} \Pi\right)$ was directly ascertained. The formation of $\mathrm{HCN}(\mathrm{X})$ and/or $\mathrm{OH}\left(\mathrm{X}^{2} \Pi\right)$ is tentatively proposed.

\section{EXPERIMENTAL}

\section{CH Radical Beam Source}

The $\mathrm{CH}$ radicals are produced in an electrical discharge. A schematic view of the radical beam source was shown in the inner panel in figure 1. The source consists of a pair of coaxial electrodes made of brass plates with a hole of $5 \mathrm{~mm}$ in diameter, teflon insulators with a cavity of $5 \mathrm{~mm}$ in diameter, and an aluminum adopter installed in front of an pulsed valve. The spacing between discharge electrodes was $8 \mathrm{~mm}$. Discharge was ignited within the area surrounded by the teflon tube and the two electrodes. Argon gas was bubbled in a methanol container at the room temperature, and the gas mixture of 1550Torr was expanded from the pulsed valve into the discharge region with the pulse width of $2 \mathrm{~ms}$. The $\mathrm{CH}$ radical was produced from decomposition of methanol by dc-discharge at the voltage of $1.8 \mathrm{kV}$. A train of pulsed beam spontaneously ignites the discharge.

\section{Crossed-beam Reaction of $\mathrm{CH}$ with $\mathrm{NO}$}

The separation of $\mathrm{CH}$ from other discharge products and the state-selection of $\mathrm{CH}$ were performed by a $60-\mathrm{cm}$ electrostatic hexapole field with a beam stop. The apparatus is schematically shown in figure 1 . The detail of the crossed-beam apparatus has been described elsewhere. ${ }^{5,6}$ The beam source and the discharge unit were 


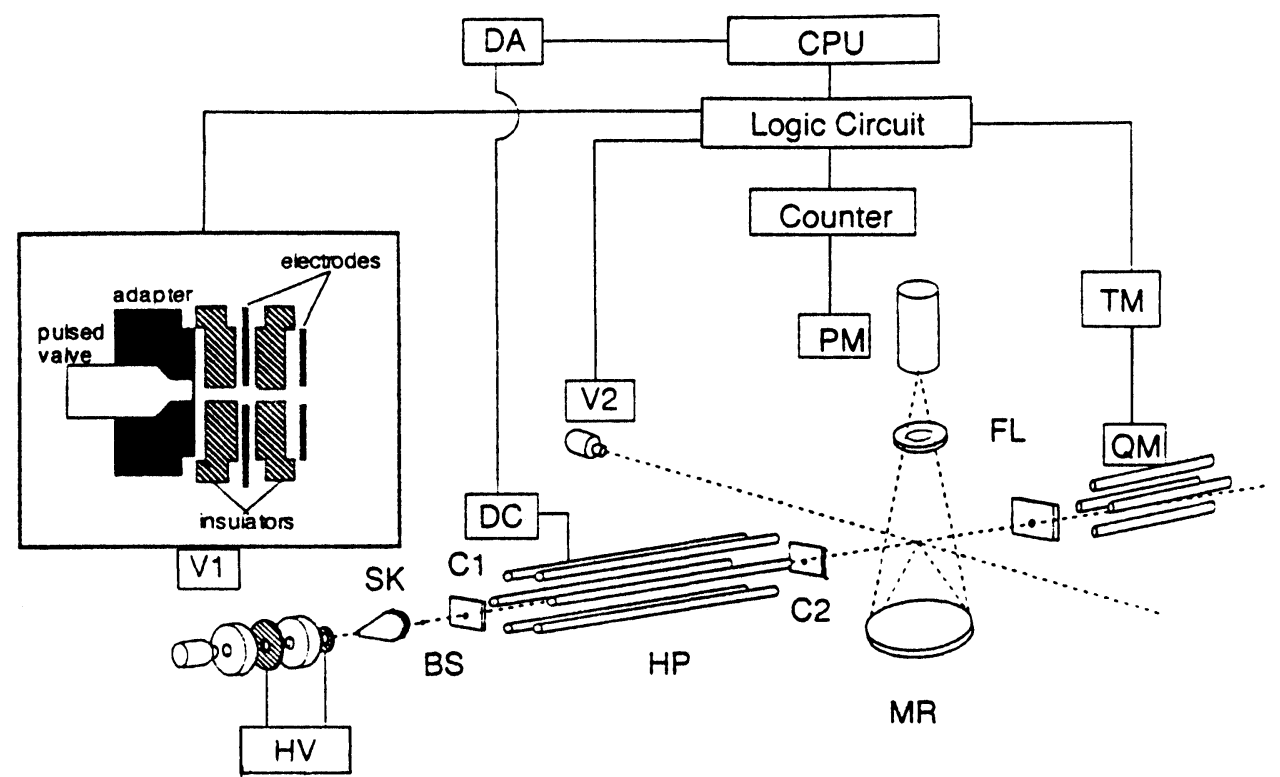

Figure 1 Schematic view of the $\mathrm{CH}$ radical beam source and the crossed beam apparatus with the $60-\mathrm{cm}$ electrostatic hexapole field. Inner panel: $\mathrm{CH}$ radical beam source. V1; $\mathrm{CH}$ radical beam source, SK; skimmer, BS; beam stop, C1; collimator 1, HP; 60-cm electrostatic hexapole field, C2; collimator 2, MR; concave mirror, FL; filter, PM; photomultiplier, V2; NO beam source, QM; quadrupole mass spectrometer, TM; transient memory.

mounted in the nozzle chamber. NO gas at 50 Torr is introduced into the reaction chamber as a pulsed free-jet and it crosses with the state-selected $\mathrm{CH}$ beam in the reaction chamber. The emission from the crossing zone was collected into a photomultiplier (Hamamatsu, R943-02) with a concave mirror, and detected by a gated photon-counting method. In order to remove the unwanted stray light from the discharge region, the background counts were subtracted every time from the crossed beam signal by the modulation of NO beam. The chemiluminescence was measured as functions of both the hexapole voltage $V_{o}$ and the wavelength of emission. The chemiluminescence was isolated by three kinds of optical filters (Toshiba, Y-42, R-65 and UV-D33S). The UV-D33S filter transmits emission from 250 to $400 \mathrm{~nm}$, the Y-42 filter transmits emission longer than $420 \mathrm{~nm}$, and the R-65 filter above $650 \mathrm{~nm}$.

\section{Focusing Curve for the CH Radical Beam}

In order to confirm the formation of the $\mathrm{CH}$ radicals, the $\mathrm{V}_{\mathrm{o}}$-dependence of the beam intensity $(\mathrm{m} / \mathrm{e}=13)$ was measured by a quadrupole mass spectrometer (MSQ-150A, ULVAC). The same radical beam source unit was mounted in another oriented beam apparatus with the $2 \mathrm{~m}$ electrostatic hexapole field which has been described previously. ${ }^{7}$ After the state-selection by the hexapole field with no beam stop, the dc-discharge products were measured by a mass spectrometer in the reaction chamber 
at $3 \mathrm{~m}$ downstream from the beam source, as a function of the hexapole voltage $\mathrm{V}_{\mathrm{o}}$ from 0 to $1000 \mathrm{~V}$ at the interval of $50 \mathrm{~V}$. By using the different experimental setup and measuring the corresponding flight times, we estimated the stream velocity, $v_{\mathrm{s}}=650 \mathrm{~ms}^{-1}$ and the perpendicular velocity, $\alpha_{\mathrm{s}}=50 \mathrm{~ms}^{-1}$ to determine the velocity distribution of the $\mathrm{CH}$ beam. These parameters were used in the Monte Carlo trajectory simulation.

\section{RESULT AND DISCUSSION}

\section{Chemiluminescence from the Reaction of $\mathrm{CH}$ with $\mathrm{NO}$}

Figure 2 shows the Vo-dependence of the chemiluminescence intensity obtained from the reaction of NO with the discharge product. The dependence exhibits a clear sharp peak at $\mathrm{V}_{\mathrm{o}}=2 \mathrm{kV}$. Since no emission was ascertained when the discharge was off,

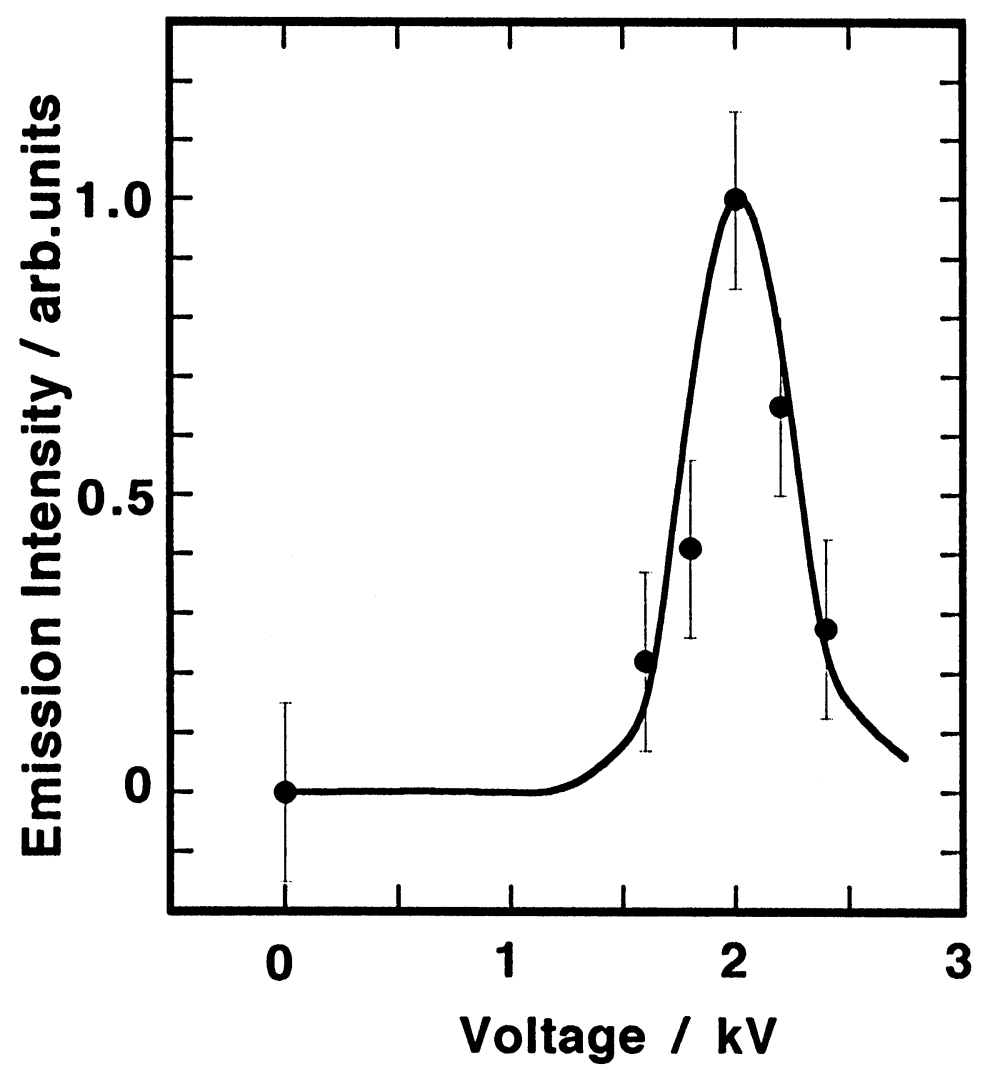

Figure 2 Dependence of chemiluminescence intensity from the reaction of $\mathrm{CH}+\mathrm{NO}$ upon the hexapole voltage.

The filled circle; experimental points. The vertical bars on the experimental points indicate the standard deviation $( \pm \sigma)$. The solid line is the calculated focusing curve for the $\mathrm{CH}$ in the $|3 / 2,3 / 2,3 / 2\rangle$ state. 
the decomposition of methanol by the dc-discharge produces reactive species which can be focused by the hexapole field and its emission gives the structured focusing curve. To make sure that this chemiluminescence is due to the reaction of pure $\mathrm{CH}$ with NO, the Monte Carlo trajectory simulation for $\mathrm{CH}$ was carried out in the same experimental conditions of 60 -cm electrostatic hexapole field with beam stop.

For the $\mathrm{CH}$ molecule in a specific rotational state of $\mid J \Omega M>$, the optimum voltage $\mathrm{V}_{\mathrm{J} \Omega \mathrm{M}}$, at which a molecule initially on the central beam axis is restored and focused to the axis, is approximately described as eq. (1). ${ }^{8}$

$$
\mathrm{V}_{J \Omega \mathrm{M}}=\pi^{2} \mathrm{v}^{2} \mathrm{R}^{3} \mathrm{~mJ}(\mathrm{~J}+1) /\left(6 \mathrm{~L}^{2} \mu \Omega \mathrm{M}\right),
$$

where $\mu$ is the permanent dipole moment, $\mathrm{m}$ the mass, $\mathrm{v}$ the velocity of the molecule, and $\mathrm{L}$ is the length, $\mathrm{R}$ the inner radius of the electric hexapole field. In this simulation, the motion of $\mathrm{CH}$ molecule in the assembly was exactly calculated by using Newton's equations with considering the velocity distribution, the angular divergence, and the geometrical arrangement of the assembly. The detail for the Monte Carlo trajectory simulation has been described elsewhere. ${ }^{7}$ The solid line is the calculated focusing curve of the $\mathrm{CH}$ beam in the $13 / 2,3 / 2,3 / 2>$ state by using the beam parameters of $\mathrm{v}_{\mathrm{s}}=650 \mathrm{~ms}^{-1}, \alpha_{\mathrm{s}}=50 \mathrm{~ms}^{-1}$ and $\mu=1.46 \mathrm{D}$. The curve shows good agreement with the experimental result, indicating that this emission was attributed to the reaction of $\mathrm{NO}$ with $\mathrm{CH}$ in the single rotational-state of $13 / 2,3 / 2,3 / 2>$. The Monte Carlo trajectory simulation also indicates that only the $13 / 2,3 / 2,3 / 2>$ state, which has the largest value of $\rho=\mathrm{M} \Omega /\left(\mathrm{J}^{2}+\mathrm{J}\right)=0.6$, can be focused in the first place at $2 \mathrm{kV}$ and other $\mid \mathrm{J}, \Omega, \mathrm{M}>$ states require higher voltages because of the small values of $\rho$. That is, $\mathrm{CH}$ has the discrete distribution of $\rho$, because the rotational state-density of $\mathrm{CH}$ radical in the $\Pi$ state, is very low owing to the large rotational constant and the definite rotational quantum number of $\Omega$. The contributions from the other discharge products can also be ruled out by the reason that they give only broad structure in the focusing curves due to the asymmetry top character of their rotational states and the quasi continuum energy gap in rotational levels ${ }^{9}$ (see appendix).

\section{Focusing Curve of the CH Radical Beam}

The focusing curve was again measured by using another machine with a longer hexapole field of $2 \mathrm{~m}$. As shown in eq. (1), the longer hexapole field requires the lower hexapole voltage to focus the $\mathrm{CH}$ radicals in the same IJ, $\Omega, \mathrm{M}>$ states. So that other states having even small values of $\rho$ can be focused.

Figure 3 shows the focusing curve measured by the mass spectrometer tuned to $\mathrm{m} / \mathrm{e}=13(\mathrm{CH})$. It is found that the intensity has a clear dependence on the hexapole voltage and the curve has peaks at the voltage of $0.1,0.2,0.4,0.6$ and $0.75 \mathrm{kV}$. The Monte Carlo trajectory simulation with the same beam parameters used above can reproduce all peaks in figure 3 as the focusing curves of the $\mathrm{CH}$ radical for three $\mid \mathrm{J} \Omega \mathrm{M}>$ states; $|1 / 2,1 / 2,1 / 2>| 3 / 2,,3 / 2,3 / 2>$ and $\mid 5 / 2,3 / 2,5 / 2>$. The measurement of other states should afford the direct evidence for the formation of $\mathrm{CH}$ radicals. Thus, it was confirmed that the separation of $\mathrm{CH}$ radical from the other discharge 


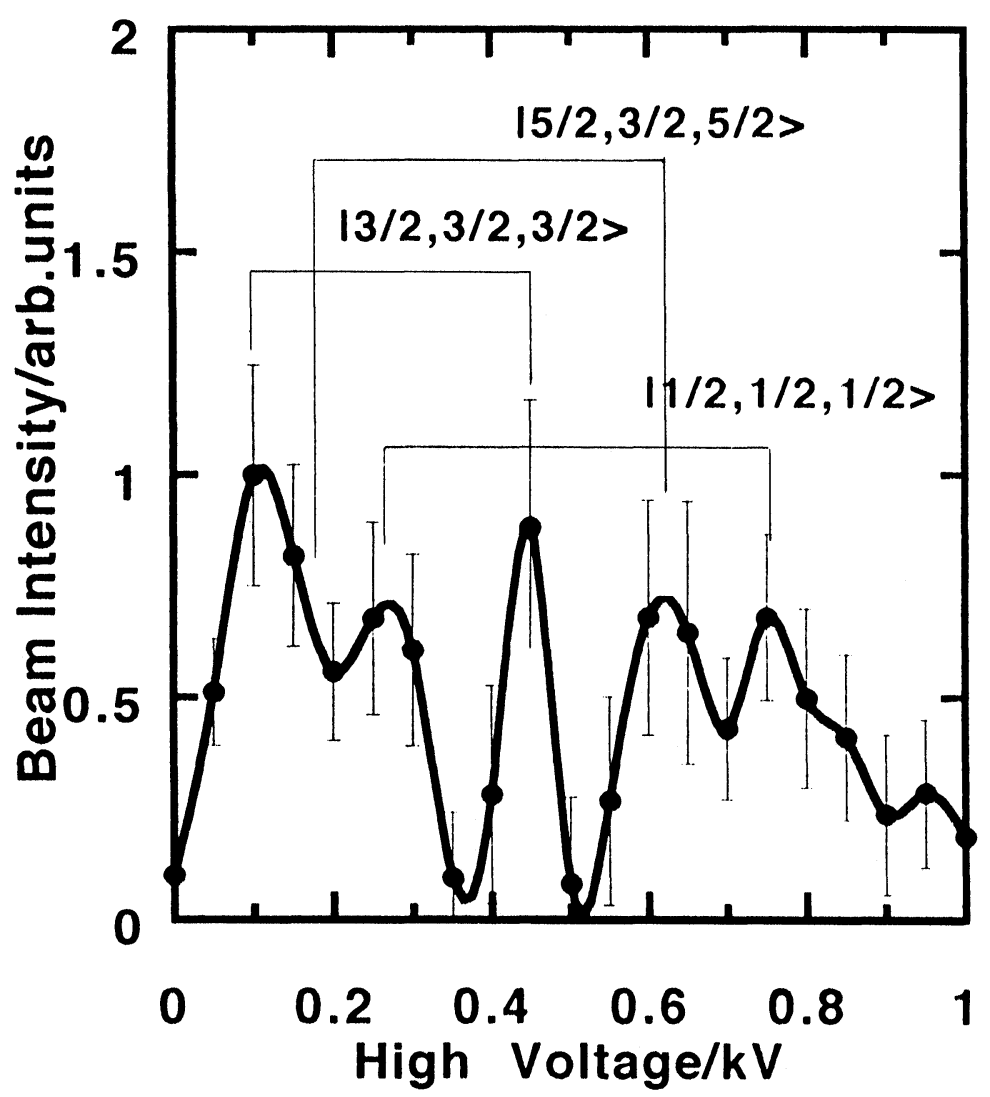

Figure 3 Dependence of the intensity of $\mathrm{m} / \mathrm{e}=13$ peak upon the hexapole voltage.

The filled circle; experimental points. The vertical bars on the experimental points indicate the standard deviation $( \pm \sigma)$. The solid curve has been drawn through the points for purpose of clarity. The vertical lines indicate the calculated peak positions for the three rotational states in the focusing curve of the $\mathrm{CH}$ radical. Each $\mid \mathrm{J}, \Omega, \mathrm{M}>$ state (i.e. $|3 / 2,3 / 2,3 / 2>| 5 / 2,,3 / 2,5 / 2\rangle$, or $\mid 1 / 2,1 / 2,1 / 2>$ ) gives two peaks, respectively.

products was successfully accomplished by the successive state-selection using the hexapole field, following rotational cooling by supersonic beam.

\section{Identification of the Emitting Product}

In order to assign the emitting product, the chemiluminescence was measured in various wavelength regions by three optical filters (Toshiba, Y-42, R-65, and UVD33S). The results were summarized in table 1.

The chemiluminescence was found to be mainly in the wavelength region longer than $650 \mathrm{~nm}$. This result suggests that $\mathrm{NH}\left(\mathrm{A}^{3} \Pi\right)$ was not expected to be produced from the reaction of $\mathrm{CH}$ with $\mathrm{NO}$. This result disagrees with the results from Lichtin et al. ${ }^{1}$ and Nishiyama et al. ${ }^{2}$, but agrees with the one from Dean et al. ${ }^{3}$ 
Table 1. Wavelength dependence of the chemiluminescence intensity measured by three kinds of filters

\begin{tabular}{lll}
\hline Filters & Wavelength region & Emission intensity \\
\hline none & $200-900 \mathrm{~nm}$ & $1.0 \pm 0.2$ \\
Y-42 & $420-900 \mathrm{~nm}$ & $0.9 \pm 0.2$ \\
R-65 & $650-900 \mathrm{~nm}$ & $0.6 \pm 0.2$ \\
UV-D33S & $250-400 \mathrm{~nm}$ & $0.1 \pm 0.2$ \\
\hline
\end{tabular}

a) The emission intensities were normalized by the transmittance of the filters.

The conceivable channels leading to exothermic products are summarized as follows. ${ }^{10}$

$$
\begin{aligned}
& \mathrm{CH}+\mathrm{NO} \rightarrow \mathrm{CO}+\mathrm{NH} \quad \Delta \mathrm{H}=-648.5 \mathrm{~kJ} \mathrm{~mol}^{-1} \\
& \mathrm{CN}+\mathrm{OH} \quad \Delta \mathrm{H}=-306.9 \mathrm{~kJ} \mathrm{~mol}^{-1} \\
& \mathrm{HCN}+\mathrm{O} \quad \Delta \mathrm{H}=-300.0 \mathrm{~kJ} \mathrm{~mol}^{-1} \\
& \mathrm{HCO}+\mathrm{N} \quad \Delta \mathrm{H}=-168.3 \mathrm{~kJ} \mathrm{~mol}^{-1} \\
& \mathrm{NCO}+\mathrm{H} \quad \Delta \mathrm{H}=-306.9 \mathrm{~kJ} \mathrm{~mol}^{-1} \\
& \mathrm{CNO}+\mathrm{H} \quad \Delta \mathrm{H}=-57.9 \mathrm{~kJ} \mathrm{~mol}^{-1}
\end{aligned}
$$

With the aid of the spectroscopic data of all possible products which could emit light, ${ }^{11,12,13}$ the present result predicts that other species such as $\mathrm{HCN}\left(\mathrm{X} ; \mathrm{v}^{\prime \prime}\right), \mathrm{HCO}(\mathrm{A})$ and $\mathrm{OH}\left(\mathrm{x} ; \mathrm{v}^{\prime \prime}\right)=4,5$ : Meinel band) can be a strong candidate as the emissive product, i.e. the reactions (b), (c), and (d) can be the product channels for this emission. Recently, Miller and Bowman ${ }^{14}$ proposed that the reaction of $\mathrm{CH}$ with NO proceeds through the singlet transition-state complex, ${ }^{1} \mathrm{HCNO}^{*}$ and this complex leads to (b) and (c) reaction paths. This mechanism seems to be consistent with our result. According to this mechanism, reaction (d) is unlikely due to the structural rearrangement required along the reaction coordinate, resulting in a much higher barrier along the reaction coordinate than reaction (b). Thus, reaction (b) and (c) would be the most likely product channels for emission. At this stage, it is difficult to identify the product uniquely, but it is concluded that $\mathrm{NH}\left(\mathrm{A}^{3} \Pi\right)$ is not expected to be produced from the reaction of $\mathrm{CH}$ with $\mathrm{NO}$.

\section{CONCLUSION}

The $\mathrm{CH}$ radical beam was produced via the decomposition of methanol by the dcdischarge in the pulsed supersonic beam. The $\mathrm{CH}$ beam was state-selected and separated from other discharge products using the hexapole field. The chemiluminescence from the crossed beam reaction of $\mathrm{CH}$ in the $\mid 3 / 2,3 / 2,3 / 2>$ state with $\mathrm{NO}$ was observed. From the spectroscopic analysis, no formation of $\mathrm{NH}\left(\mathrm{A}^{3} \Pi\right)$ was directly ascertained, and the formation of $\mathrm{HCN}(\mathrm{X})$ and/or $\mathrm{OH}\left(\mathrm{X}^{2} \Pi\right)$ was proposed. 


\section{APPENDIX}

\section{Estimation of the Contribution from Other Discharge Products}

From the consideration on the molecular symmetry and the Monte Carlo trajectory simulation of the focusing curves, the contributions from other discharge products to the chemiluminescence can be ruled out. The symmetries of other discharge products from methanol and their behaviors in the electrostatic hexapole field are shown in table 2 .

Table 2. Symmetries of the discharge products from methanol and their behaviors in the electrostatic hexapole field

\begin{tabular}{llll}
\hline species & symmetry & type of molecule & focusing curve expected \\
\hline $\mathrm{CH}_{3}$ & $\mathrm{D}_{3 \mathrm{~h}}$ & sym & - \\
$\mathrm{CH}_{2}$ & $\mathrm{C}_{2 \mathrm{v}}\left(\mathrm{D}_{\text {ooh }}\right)$ & asym (asym) & monotonous (-) \\
$\mathrm{CH}_{2} \mathrm{OH}$ & $\mathrm{C}_{\mathrm{s}}$ & asym & monotonous \\
$\mathrm{CHOH}$ & $\mathrm{C}_{\mathrm{s}}$ & asym & monotonous \\
$\mathrm{CH}_{2} \mathrm{O}$ & $\mathrm{C}_{2 v}$ & asym & monotonous \\
$\mathrm{CHO}^{\mathrm{O}}$ & $\mathrm{C}_{\mathrm{s}}$ & asym & monotonous \\
$\mathrm{CH}_{3} \mathrm{O}$ & $\mathrm{C}_{3 \mathrm{v}}$ & sym & monotonous \\
$\mathrm{CH}$ & & sym & structured \\
\hline
\end{tabular}

a) asym; asymmetric top, sym; symmetric top.

Owing to the molecular symmetry, the $\mathrm{CH}_{3}$ and the $\mathrm{CH}_{2}\left(\mathrm{D}_{\circ \mathrm{oh}}\right)$ radicals are expected to have no permanent dipole moment. Therefore, they cannot be focused by the electrostatic hexapole field. As for the $\mathrm{CH}_{2}\left(\mathrm{C}_{2 \mathrm{v}}\right)$ radical and other polar species, except for the $\mathrm{CH}$ radical and the $\mathrm{CH}_{3} \mathrm{O}$ (methoxy) radical, they show no clear structure in focusing curve, because the state-selection of the single rotational state is hardly possible due to their asymmetry top character of their rotational states and quasi continuum energy gap for rotational levels. ${ }^{9}$

Except for the $\mathrm{CH}$ radical, only the methoxy radical is expected to be a candidate which could be done the selection of single state by the hexapole field. However, this possibility is also ruled out by the following reason: As for the methoxy radical which has an unpaired electron at the oxygen atom ${ }^{15}$, the internal couplings, such as the Jahn-Teller and spin-orbit effect, cause the situation that the various axial components (the electron-spin, the vibration, the electron-orbital angular momentum and $\mathrm{K})$ are not good quantum numbers. ${ }^{16}$ Instead of these quantum numbers, only $\mathrm{G}$ is well known as a good quantum number. ${ }^{17}$ In order to check the contribution of the methoxy radical, the focusing curve of methoxy radical was calculated by the Monte Carlo trajectory simulation for the ideal case that $\mathrm{K}$ is a good quantum number. For the permanent dipole moment of methyl radical is not known experimentally, the calculated value of $2.11 \mathrm{D}^{18}$ was used for the simulation. The focusing curve of the methoxy radical was found to be monotonous. The actual focusing curve of should be simpler than the simulated one, because actual $\mathrm{CH}_{3} \mathrm{O}$ states should be given by the quantum number $\mathrm{G}$ rather than $\mathrm{K}$, the distribution of $\rho$ becomes more continual than in the ideal case with $K$. Thus, the focusing curve of the methoxy radical should be monotonous in structure. 


\section{References}

1. D. A. Lichtin, M. R. Bermun, M. C. Lin, Chem. Phys. Lett. 108, 18 (1984)

2. N. Nishiyama, H. Sekiya, S. Yamaguchi, M. Tsuji and Y. Nishimura, J. Phys. Chem. 90, 1491 (1986)

3. A. J. Dean, R. K. Hanson and C. Bowman, J. Phys. Chem. 95, 3180 (1991)

4. M. Takezaki, H. Ohoyama, T. Kasai and K. Kuwata, Fifteenth International Symposium on Molecular Beams A. 5.1 (1993)

5. H. Ohoyama, T. Kasai, K. Ohashi and K. Kuwata, Chem. Phys. 165, 255 (1992)

6. D. C. Che, T. Kasai, H. Ohoyama, K. Ohashi, T. Fukawa and K. Kuwata, J. Phys. Chem. 95, 8159 (1991)

7. T. Kasai, T. Fukawa, T. Matsunami, D. C. Che, K. Ohashi, Y. Fukunishi, H. Ohoyama and K. Kuwata, Rev. Sci. Instrum. 70, 3864 (1993)

8. K. H. Kramer and R. B. Bernstein, J. Chem. Phys. 42, 767 (1965)

9. C. H. Townes and A. L. Schawlow, Microwave Spectroscopy (Dover Publications, Inc., 1955)

10. M. W. Chre, C. A. Davies, J. R. Downey, D. J. Frurip, R. A. McDonald and A. N. Syverud, JANAF Thermochemical Table 3rd Edition, Journal of Physical and Chemical Referencd Data volume 14, 1985

11. G. Hertzberg, Spectra of Diatomic Molecules' (Litton Educational Publishing, Inc., 1950)

12. R. W. B. Pearse and A. G. Gaydon, The Identification of Molecular spectra (Chapman and Hall, 1976)

13. G. Hertzberg, Electronic Spectra of Polyatomic Molecules (Litton Educational Publishing, Inc., 1966)

14. J. A. Miller and C. T. Bowman, Prog. Energy Combust. Sci., 15, 287 (1989)

15. D. R. Yarkony, H. F. Schaefer and S. Rothenberg, J. Am. Chem. Soc. 96, 656 (1974)

16. D. K. Russell and H. E. Radfoed, J. Chem. Phys. 72, 2750 (1980)

17. J. T. Hougen, J. Chem. Phys. 37, 1433 (1962)

18. C. F. Jackels, J. Chem. Phys. 76, 505 (1982) 